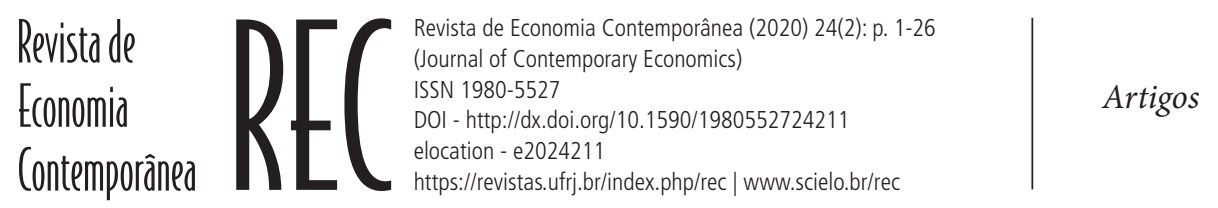

\title{
CARDIM, KEYNES E MARX: UM DIÁLOGO INTERROMPIDO?
}

\begin{abstract}
Gentil Corazza $a^{a}$
aProfessor titular da Universidade Federal do Rio Grande do Sul (UFRGS). Porto Alegre, RS, Brasil. ORCID: https://orcid.org/0000-0002-5382-5597.
\end{abstract}

Recebido em 11 de dezembro de 2018

Aceito em 04 de junho de 2019

RESUMO: O objetivo deste texto é analisar o diálogo entre Keynes e Marx, em textos de Fernando Cardim de Carvalho. Embora o tema não seja novo, o diálogo tentado por Cardim apresenta particularidades. Ele se propõe analizar a teoria monetária de Marx a partir de uma perspectiva pós-keynesiana, mas outros temas também são objeto de comparação entre Marx e Keynes. A pergunta, que procuramos responder, é a seguinte: o diálogo buscado por Cardim teria sido realmente interrompido durante de seu mestrado ou estaria presente de forma implícita ao longo de sua carreira acadêmica? Buscando analisar essas questões, além da introdução e da conclusão, o texto aborda ainda os encontros e desencontros de Cardim com Marx, a teoria monetária de Marx, numa perspectiva pós-keynesiana e os pontos de convergência e divergência entre Marx e Keynes em textos de Fernando Cardim de Carvalho.

PALAVRAS-CHAVE: Cardim de Carvalho; Marx; Keynes; teoria monetária.

CLASSIFICAÇÃO JEL: E11; E12. 


\title{
CARDIM, KEYNES AND MARX - AN INTERRUPTED DIALOG?
}

\begin{abstract}
This text analyses the dialogue between Keynes's and Marx's ideas in Fernando Cardim de Carvalho's works. This subject is not a novelty, but Cardim's endeavour has certain peculiarities. He sets out an analysis of Marx's monetary theory from a post-Keynesian perspective but also goes over into how their ideas converge or diverge in relation to monetary theory. Looking into Cardim de Carvalho's academic career, the main question driving our discussion here is whether the dialogue between Keynes's and Marx's ideas in his works was effectively interrupted during his master's degree or it remained implicit in all of his works, throughout his entire career.
\end{abstract}

KEYWORDS: Cardim de Carvalho; Marx; Keynes; monetary theory. 


\section{INTRODUÇÃO}

O objetivo deste texto é analisar os termos de um diálogo com Marx iniciado pelo professor Fernando Cardim Carvalho durante seu período de formação universitária e interrompido posteriormente, no final de seu mestrado e início de seu doutorado. Trata-se, evidentemente, de um grande desafio, pois o tema é complexo e o material disponível sobre o assunto é reduzido.

Explorar o diálogo implícito ou explícito entre grandes pensadores é muito frequente. Muitos textos já foram escritos com o objetivo de analisar similitudes e diferenças entre o pensamento de Marx e de Keynes. Tais iniciativas têm sido mais frequentes a partir de autores do campo marxista do que de autores do campo pós-keynesiano. Em textos anteriores (CORAZZA, 1994, 1998) caminhamos nesse sentido. Há mesmo autores, como é o caso de Mollo (2017), que se intitula "marxista e pós-keynesiana”. Alguns textos buscam comparar o pensamento de Marx e o de Keynes de forma abrangente, como é o caso de Dillard (1984). Outros, como Braga (1985) e Prado (2016), procuram comparar temas específicos, como a questão da demanda efetiva de Keynes e o processo de acumulação de capital de Marx. Vercelli (1985) faz um amplo estudo comparativo sobre a questão da instabilidade estrutural do sistema capitalista no pensamento de Marx, Keynes e Schumpeter. No entanto, não é objetivo deste texto retomar esse debate, comparando o pensamento de Marx e Keynes de forma ampla, nem tampouco buscar aproximar questões específicas da teoria de Marx e da de Keynes na vasta obra do professor Cardim. O que se procura de forma específica é analisar os pontos de convergência ou de divergência entre o pensamento de Marx e o de Keynes levantados expressamente pelo próprio Cardim, com o objetivo de tentar responder se o diálogo com Marx, iniciado por Cardim durante sua formação, teria sido realmente interrompido a partir do momento em que ele fez sua opção teórica pelo pensamento pós-keynesiano.

O diálogo proposto entre Marx e Keynes está centrado no tema da teoria monetária de Marx, que Cardim entende ser uma questão central pela qual aquele autor pensa a dinâmica capitalista e busca analisar sua possível integração com o princípio da demanda efetiva de Keynes. Esse diálogo também está caracterizado por particularidades associadas a suas próprias posições teóricas. Com efeito, Cardim estudou Marx ainda no curso de graduação em economia na Universidade de São Paulo (USP) e principalmente durante seu mestrado na Universidade Estadual de Campinas (Unicamp), mas definiu sua opção teórica pelo pós-Keynesianismo ainda durante seus estudos de mestrado. No entanto, é possível supor que não teria abandonado os estudos sobre Marx durante seu doutorado, pois um dos primeiros textos (se não mesmo o primeiro) que publica (CARVALHO, 1986), após concluir os estudos de doutora- 
mento, surpreendentemente teve como tema a teoria monetária de Marx, uma questão que ainda não era central nos estudos sobre Marx entre os próprios autores marxistas. Também não deixa de ser surpreendente que seu último texto publicado antes de falecer tenha sido uma espécie de balanço de sua relação com o pensamento de Marx. É a partir dessas questões que procuraremos analisar os termos em que Cardim procurou estabelecer este diálogo entre Keynes e Marx e ao mesmo tempo nos perguntar se tal diálogo teria de fato sido interrompido. Buscando atingir esse objetivo, além desta introdução e de uma breve conclusão, o texto aborda ainda, na seção 1, os encontros e desencontros de Cardim com Marx; na seção 2, a teoria monetária de Marx em uma perspectiva pós-keynesiana; e, na seção 3, procura-se analisar pontos de convergência e divergência entre Marx e Keynes apresentados no texto de Cardim sobre a teoria monetária de Marx (CARVALHO, 1986). Na conclusão, são destacados os principais pontos aqui abordados, procurando-se responder à pergunta formulada na introdução se o referido diálogo de Keynes com Marx foi realmente interrompido a partir de opção teórica de Cardim pela teoria pós-keynesiana.

\section{ENCONTROS E DESENCONTROS COM MARX}

Em seu último texto publicado, ainda em vida, no jornal Valor Econômico de 27/04/2018, poucos dias antes de sua morte, ocorrida em 17 de maio de 2018, Cardim narra que seu encontro com Marx deu-se, "de forma esporádica e fragmentada, quando ainda era estudante de graduação em economia na USP” (CARVALHO, 2018). Reinava ali um ambiente em que Marx, além de não ser muito popular, era quase totalmente desconhecido pelo corpo de professores. Mesmo assim, Cardim dedicou-se a ler o primeiro volume de O Capital. Coisa diferente ocorreu durante seu mestrado no Instituto de Economia da Unicamp, onde Marx era o autor dominante em meados dos anos 1970. Foi ali que procurou aprofundar suas leituras sobre esse autor, num momento em que já se sentia atraído pela teoria pós-keynesiana, que efervescia naqueles anos. Relata que, embora achasse entediantes muitos dos temas abordados por Marx, foi atraído pelas discussões sobre o “jovem Marx”, cuja teoria da alienação lhe parecia ter aspectos comuns com o tema da incerteza e da tomada de decisões em Keynes. O tema da alienação do jovem Marx, também abordado por autores como Rubin (1979) e Mészáros (1975), despertava seu interesse por tratar da ação humana no contexto da reificação das relações sociais de produção, ou seja, uma situação em que o produtor perde o controle sobre o produto resultante de sua atividade. No contexto da teoria da alienação de Marx, Cardim conclui que "o agente econômico age em um ambiente que lhe é estranho, mesmo que este ambiente tenha sido produzido por ele" (CARVALHO, 
2018). Ora, continua ele, "esse é também o quadro em que o conceito de incerteza proposto por Keynes se define, isto é, um ambiente construído, mas não reconhecido pelo indivíduo" (ibidem). Poderíamos dizer que, para Cardim, a raiz da incerteza keynesiana estaria numa situação não controlada pelos empresários, um contexto em que não há base segura para fazer previsões racionais sobre o futuro do investimento. Um contexto semelhante seria o da alienação de Marx, em que está mergulhado o trabalhador, que perde o controle sobre o produto de seu trabalho. Tanto os empresários de Keynes quanto os trabalhadores de Marx são dominados pelo contexto que ajudaram a criar. Essa aproximação do conceito de alienação de Marx com o conceito de incerteza de Keynes será objeto de análise mais adiante neste trabalho.

Em entrevista ao Blog da Associação Keynesiana Brasileira (AKB) de julho de 2011 (CARVALHO, 2011), Cardim relata que, quando foi fazer o mestrado em economia na Unicamp, em 1976, já estava motivado para aprofundar seus estudos sobre Keynes, objetivo que foi se fortalecendo no decorrer do tempo - apesar de que no mestrado a ênfase teórica se concentrasse quase inteiramente em Marx e Kalecki e não em Keynes, devido aos conceitos keynesianos de incerteza e expectativas, que não se enquadravam muito bem na perspectiva de Marx, que supostamente lidava com conceitos mais estruturais.

Perguntado se sua escolha teórica teve alguma relação com sua visão política do mundo, Cardim respondeu afirmativamente e explicou que teve uma formação fundamentalmente marxista na juventude, que era compatível com valores como a luta contra a desigualdade, a luta pela ampliação dos direitos e a democracia, temas muito caros sobretudo ao "Jovem Marx", cujos textos ainda o continuam interessando. Porém, com o passar do tempo, "os fundamentos teóricos da abordagem de Marx foram aparecendo, para mim, como muito mais frágeis do que eu julgava inicialmente" (CARVALHO, 2011). Por outro lado, a encarnação política do marxismo em regimes do tipo soviético representava "a negação de tudo o que se esperava caracterizar um mundo melhor" (CARVALHO, 2011). Ao mesmo tempo, reconheceu que "não se pode imputar a Marx os resultados do chamado marxismo-leninismo, já que Marx não viveu para se posicionar a respeito, ainda que seja possível inferir de seus trabalhos que ele talvez fosse muito crítico do que se fez depois em seu nome" (CARVALHO, 2011). No entanto, ser marxista, para ele, implicaria o compartilhamento de visão totalizante sobre o papel de indivíduos numa sociedade de classes, pois considerava que o marxismo moldava a vida e o comportamento dos seus adeptos, sendo, inclusive, até a escolha de amigos influenciada por essa escolha teórica. Ele não podia se sentir confortável nessa situação. Seu afastamento de Marx se aprofundava à medida que via conhecidos seus defenderem, por exemplo, "genocidas como Stálin ou Mao", como afirmou (CARVALHO, 2011). Além das dificuldades e objeções teóricas que encontrou para incorporar as ideias de Marx, 
essas razões de ordem política e ideológica contribuíram para seu seu afastamento progressivo do pensamento de Marx.

Além disso, Cardim atribuiu à crescente insatisfação com essa alternativa o fato de ter procurado outros caminhos nos quais a preocupação com a redução das desigualdades e a defesa do trabalho pudessem conviver com regimes democráticos. Fatores como esses teriam contribuído para que se dedicasse a estudar as experiências social-democratas e socialistas democráticas bem sucedidas, como as dos países nórdicos, apoiadas em instituições duráveis, as quais lhe pareciam compatíveis com a teoria keynesiana, que havia influenciado aquelas experiências da social-democracia.

A partir dessas definições de caráter social e político, o desencontro de Cardim com Marx parece ter iniciado com sua crítica a uma certa literatura marxista que se assemelhava mais a jogos vazios de palavras, raciocínios circulares, muito esforço destinado mais a provar que a teoria era praticamente invulnerável à crítica teórica ou empírica, mesmo nas suas partes mais frágeis. Por essas razões, afirma ter saído de Campinas já convencido de que seu desencontro com Marx não demoraria a vir. A separação se deu ao fim dos anos 1970, início dos 1980, e foi causada por fatores de atração relacionados à teoria pós-keynesiana e de repulsão a aspectos relacionados tanto à visão teórica de Marx quanto ao que denominaria de características do marxismo. Não resta dúvida de que a atração da teoria pós-keynesiana teria sido decisiva para apressar seu desencontro e afastamento em relação a Marx. Dentre os fatores de repulsão, Cardim aponta uma certa "linguagem marxista", a "natureza totalizante" do marxismo, que o distingue de outras escolas de pensamento social (CARVALHO, 2018). Acentua também que a opção por uma escola de pensamento não necessita moldar toda sua vida e o "marxismo molda sua vida e comportamento de modo que nenhuma outra teoria social o faz" (ibidem). Você pode ser keynesiano ou neoclássico, dizia Cardim, sem que isso influenciasse sua vida toda, mas ser marxista, para ele, significava compartilhar a visão de mundo segundo a qual até a escolha de amigos chega a ser pautada pela ideologia. Questões como essas provocavam nele um grande desconforto intelectual.

No entanto, como relata, "o principal fator de afastamento é a visão de ciência proposta por Marx” (CARVALHO, 2018), a qual acarreta consequências problemáticas e negativas sobre o modo como pesquisadores marxistas tratam a informação empírica. Para Cardim, a exemplo das ciências naturais, o trabalho científico não busca explicar "essências", ocultas por baixo das aparências. As ciências naturais buscam identificar padrões nos dados que se observam, naquilo que aparece. É como olhar para um tabuleiro, exemplifica ele, e buscar a ordem nas peças, a ciência moderna não olha embaixo do tabuleiro. Ela olha o que está em cima. A informação com que lida é sempre visível e seu problema é separar o sistemático do acidental, não a essência da aparência. A explicação científica do mundo deve ser buscada na informação empí- 
rica. Se a informação que se tem à disposição for insuficiente, busque-se mais. Como exemplo, Cardim cita o esforço para verificar as "leis" de tendência da queda da taxa de lucro, ou a da miséria crescente dos trabalhadores, frente à evidência empírica de que nenhuma dessas "leis" realmente resistia ao exame empírico. Há, também, o conceito-chave de "classes sociais", que não exibem as características esperadas por Marx. Cardim termina sua narrativa dos encontros e desencontros com Marx dizendo que seu encontro durou relativamente pouco, embora ainda tenha interesse em trabalhos do próprio Marx, especialmente os que tratam de problemas como a teoria da alienação. No entanto, reconhece que "a separação já teria sido consumada há algum tempo" (CARVALHO, 2018).

Evidentemente, não cabe aqui tentar ampliar a discussão sobre as razões que motivaram o desencontro de Cardim com o pensamento de Marx. Trata-se de tema complexo e polêmico, que demandaria estudos mais aprofundados para ser esclarecido. Em vez disso, parece mais pertinente perguntar-se pelas razões que o teriam motivado a escrever o texto sobre a teoria monetária de Marx, no qual busca articular a teoria da demanda efetiva de Keynes com a teoria da acumulação de Marx. Nesse texto, deixa entender que haveria muitos pontos de convergência entre Marx e Keynes, como tentaremos explicitar mais adiante neste trabalho. Ao expor seus encontros e desencontros com Marx, Cardim não faz referência a esse seu texto sobre a teoria monetária de Marx. É deveras intrigante que, após ter decidido se afastar de Marx enquanto fazia o mestrado, e ao menos durante os seis anos seguintes, logo após ter concluído o doutorado, seu primeiro texto tenha sido justamente sobre Marx. E não apenas sobre Marx: é intrigante que o texto tenha tratado precisamente da questão da moeda, quando esse não era ainda um tema central entre os próprios autores marxistas. Basta lembrar que, entre autores marxistas, um dos primeiros e esparsos textos sobre a questão monetária em Marx foi La monnai chez Marx de Suzanne de Brunhoff (1967). Por que teria Cardim tentado estabelecer um diálogo entre Marx e Keynes justamente a partir da questão monetária? Por que, logo após ter defendido sua importante tese sobre Keynes e o pensamento pós-keynesiano, buscou fazer uma comparação com a teoria monetária de Marx, que dizia ter abandonado alguns anos antes? Por que não deu ele continuidade ao diálogo entre Keynes e Marx ao longo de sua carreira acadêmica? Por que teria ele se sentido motivado a fazer um balanço de sua relação teórica com Marx, após 32 anos de seu primeiro e único texto sobre o tema?

Várias respostas podem ser aventadas. Embora tenha afirmado haver abandonado Marx, isso de fato parece não ter ocorrido de forma tão clara e definitiva, como dá a entender em sua entrevista para o Blog da AKB (CARVALHO, 2011) e no texto do Valor Econômico (CARVALHO, 2018). Além disso, embora não mais tenha escrito sobre Marx, durante toda sua longa e profícua carreira acadêmica, seu último texto 
(CARVALHO, 2018), poucas semanas antes de morrer, tratou precisamente de sua relação com Marx. Conforme seu relato, a ruptura com Marx teria se dado na passagem dos anos 1970 para 1980, entre o fim do mestrado e o início do doutorado. Mesmo assim, é surpreendente que um dos primeiros textos publicados, (se não mesmo o primeiro) no mesmo ano de conclusão de seu doutorado, tenha sido sobre a teoria monetária de Marx, numa perspectiva pós-keynesiana. A partir dessas informações seria possível inferir que, mesmo após ter feito sua opção teórica pela corrente pós-keynesiana, a preocupação de Cardim com Marx foi muito além do que aqueles dois textos poderiam sugerir. Todas essas coincidências poderiam indicar que, no final da vida, Marx ainda o inquietava.

\section{TEORIA MONETÁRIA DE MARX: ALÉM DA MOEDA-MERCADORIA ${ }^{1}$}

Ao analisar a teoria monetária de Marx, numa perspectiva pós-keynesiana, Cardim destaca alguns de seus pontos essenciais (CARVALHO, 1986, p. 9). Primeiro, seguindo Marx, afirma que a natureza da moeda se altera de acordo com a natureza do sistema econômico em que se insere. Segundo, e talvez o mais relevante, embora a perspectiva da moeda-mercadoria esteja presente na teoria de Marx, muito mais por razões históricas do que teóricas, Cardim define a essencialidade da moeda, não como uma coisa material, mas como a reificação ou a materialização de uma relação social. Ou seja, ele distingue claramente a natureza da moeda, como algo social e não material, em relação ao meio material que carrega ou representa esta relação social, procedimento também realizado por Marx. Terceiro, a moeda-mercadoria é relevante apenas para a sua função de medida dos valores e não para as demais funções. Se a moeda deixa de desempenhar esta função de medir valores, isso não significa abandonar a teoria do valor trabalho de Marx. Para Cardim, em vez de medir valores ela pode desempenhar essa função mediante sua relação com os preços monetários. Por último, a teoria monetária de Marx não só sobrevive sem a perspectiva da moeda-mercadoria, mas requer essa superação para que possa ser plenamente desenvolvida.

Cardim concorda com Marx que a gênese da moeda está associada ao desenvolvimento das trocas de tal forma que ela se define como "valor de troca materializado" (CARVALHO, 1986, p. 11). Para Marx, oriunda do sistema de trocas em geral, a moeda

\footnotetext{
1 Em trabalhos anteriores (CORAZZA, 1994, 2002) analisamos exaustivamente esta questão, motivo pelo qual neste texto nos limitamos em resumir a análise e as conclusões feitas por Cardim ao reproduzir a teoria monetária de Marx.
} 
tem sua natureza historicamente condicionada pelas mudanças da natureza do sistema econômico em que está inserida. As passagens importantes dos Grundisse (MARX, 1977), citadas por Cardim, acentuam esse caráter histórico da natureza da moeda em Marx, que evolui de acordo com o modo de produção em que está inserida. Como "encarnação do valor de troca" a moeda só estará plenamente desenvolvida quando o próprio valor de troca também atingir seu pleno desenvolvimento, ou seja, quando a relação capital e trabalho assalariado estiver plenamente desenvolvida. Essa transformação plena da natureza da moeda se consome quando a finalidade da economia deixa de ser a produção de mercadorias e passa a ser a de aumentar o mais-valor na forma monetária, transformação que se expressa na mudança da fórmula de $\mathrm{M}$ - D - M, para a de D - M - D', ou seja, que no modo de produção capitalista, a moeda-dinheiro (D) deixa de ser apenas meio de troca entre duas mercadoria (M), para se transformar em capital-dinheiro e dominar todo o processo de acumulação e valorização do capital (D’). Ao mesmo tempo, no modo de produção capitalista, a moeda é o único meio de validação social do trabalho empregado na produção, motivo pelo qual a moeda torna-se a encarnação da generalidade do valor de troca em contraste com a multiplicidade dos valores de uso.

No seu texto sobre a moeda em Marx (CARVALHO, 1986), Cardim destaca que peculiaridades do ouro ou da prata, enquanto objetos, explicam apenas sua escolha para representar a relação monetária, mas elas "não se confundem porém com as características da moeda que é essencial e primariamente uma relação social, não um objeto" (p. 10). Assim, procura ele separar a teoria monetária de Marx do problema da moeda-mercadoria, sem o que seria difícil seu pleno desenvolvimento de modo a poder explicar as complexas relações monetárias e financeiras da atualidade capitalista. A perspectiva da moeda-mercadoria também dificulta qualquer comparação com a teoria monetária de Keynes. Cardim deve ter percebido que o apego à moeda-mercadoria por parte de Marx e de autores marxistas tornaria irrelevante essa teoria para entender os processos monetários e financeiros do capitalismo atual. No entanto, a análise crítica que faz da teoria da moeda-mercadoria não vai no sentido de abandonar a teoria monetária de Marx e sim, ao contrário, no sentido de mostrar que sua teoria monetária é muito mais ampla e complexa do que a perspectiva da moeda-mercadoria. Ele conclui, então, que a teoria monetária de Marx sobrevive sem a moeda-mercadoria e pode ser desenvolvida de modo a poder explicar as questões monetárias e financeiras da atualidade (CARVALHO, 1986).

Para tanto, Cardim retoma o caminho percorrido por Marx na construção de sua teoria monetária, no volume I de O Capital, (MARX, 1983a) no qual aborda a gênese lógica da forma dinheiro. Ele, porém, não se detém nessa parte mais conceitual da moeda e aponta para seus desdobramentos contidos nos Grundrisse (MARX, 1977) e 
no volume III de O Capital (MARX, 1981), no qual o autor faz uma "detalhada discussão do papel da moeda e das relações financeiras no modo de produção capitalista, permitindo levar adiante com alguma segurança a discussão de sua teoria monetária” (CARVALHO, 1986, p. 7). No entanto, nesse texto, o autor não avança sua análise de modo a abranger esse desenvolvimento da teoria monetária de Marx. Ele se limita a analisar a natureza, o conceito e a importância da moeda no pensamento de Marx, bem como a contornar o obstáculo da moeda-mercadoria de modo a afirmar sua validade e importância para explicar os fenômenos monetários e financeiros da atualidade e, assim, poder fazer uma avaliação das similitudes e diferenças entre Marx e Keynes. Esta operação de superar a restrição da moeda-mercadoria em Marx, tendo em vista seu desenvolvimento posterior, é feita a partir de uma perspectiva pós-keynesiana, como o indica o próprio título do artigo.

A moeda e a relação monetária, que se originam no processo de troca e se desenvolvem juntamente com as transformações da economia, precisam se materializar em algo que possa ser o portador dessa relação social expressa no valor de troca. Historicamente esse papel foi desempenhado pelos metais preciosos. Para Cardim, como para muitos autores marxistas, a teoria monetária de Marx está ancorada na moeda-mercadoria. É mesmo possível que Marx tivesse permanecido preso às circunstâncias históricas da moeda-mercadoria, com valor intrínseco, o que se convencionou chamar de sistema de "padrão-ouro". E a conclusão de Cardim parece lógica: “fosse esse o fim da história, a teoria monetária de Marx teria pouca relevância em termos modernos" (CARVALHO, 1986, p. 14). Porém, como afirma mais adiante, para ele a versão da moeda-mercadoria não é o fim da história e se propõe resgatar a validade da teoria de Marx, rediscutindo a questão da substância do dinheiro no próprio Marx.

Dentre as funções básicas da moeda em Marx (representante das mercadorias, medida dos valores, meio de circulação, meio de entesouramento e meio de pagamento) a moeda-mercadoria, enquanto suporte material do valor de troa, é realmente importante apenas para a mesma desempenhar a função de medida dos valores. De acordo com Marx, somente a moeda-mercadoria poderia desempenhar esse papel de medir valores, na medida e na proporção de seu próprio valor intrínseco. Cardim reafirma a posição de Marx, ao reconhecer que o dinheiro, como relação social, precisa ser representado por algo concreto, mas alerta que é preciso distinguir as características do meio de representação e o conteúdo que é representado por esse instrumento. Ou seja, que é necessário separar as duas coisas contidas na moeda-ouro: a mercadoria ouro em si mesmo e o valor de troca nela representado. A mercadoria-ouro é uma coisa e o valor de troca é outra coisa de natureza diferente, ou seja, a relação social valor de troca.

A dificuldade em se abandonar a perspectiva da moeda-mercadoria diz respeito a sua função de medida dos valores, pois, enquanto medida, a moeda precisa ser algo 
material, mercadoria, com valor intrínseco proporcional ao tempo de trabalho social, como acentuou o próprio Marx. Por isso, em sua função de medida dos valores, a substância material da moeda é essencial, mas para as demais funções a "substância material” de que fala Marx não é relevante. Como meio de circulação, o valor da moeda não depende de substância material, pois aqui a moeda é apenas símbolo de valor e o importante é que este símbolo tenha aceitação geral, independentemente de ser mercadoria ou não. Enquanto símbolo, a moeda pode ser representada por qualquer material em que a relação seja grafada, uma cédula de papel ou mesmo um lançamento contábil.

Lembra também ele que Marx já havia alertado que a moeda-mercadoria não era uma coisa simples, como poderia parecer à primeira vista, mas uma coisa complexa, era duas coisas numa só, valor ou riqueza social representada por um objeto material. A moeda "se torna uma mercadoria como as outras, mas, ao mesmo tempo, não é uma mercadoria como as outras” (MARX, 1977 p. 151). Por isso, conclui ele que:

É mais adequado, numa visão marxista, postular que a substância da forma dinheiro não é a mercadoria em que ela é representada, mas a quantidade de riqueza à disposição da sociedade (inclusive a força de trabalho potencial) em que o dinheiro pode ser convertido. Se isto é correto, a proporção em que o dinheiro é convertido em outras mercadorias é libertada da necessidade de corresponder ao valor de uma dada mercadoria-moeda. Esta proporção depende do preço das mercadorias. (CARVALHO, 1986, p. 17)

Dessa forma, "enquanto materialização de uma relação social, o caráter simbólico do dinheiro é ainda mais importante e seu papel pode ser desempenhado por qualquer material em que a relação seja grafada" (CARVALHO, 1986, p. 14).

Relevante também sua observação de que, em Marx, a natureza teórica da moeda não se esgota nesse episódio histórico em que ela se fixou como moeda-ouro. Essa distinção entre a natureza teórica da moeda, definida como valor de troca objetivado, e o objeto material que a representa é de fundamental importância, pois separa o metal ouro, como portador da relação monetária, da própria relação monetária, em si mesma, que é uma relação social, pois esta não se confunde com e não se esgota na representação metálica. As particularidades dos metais que representam essa relação "não se confundem com as características da moeda, que é essencial e primariamente uma relação social, não um objeto" (CARVALHO, 1986, p. 10).

Partindo da afirmação de Marx de que a mercadoria e as relações de troca representam a reificação das relações sociais, Cardim acentua que essa reificação atinge seu ápice quando as relações monetárias estão plenamente desenvolvidas. A moeda se 
torna plenamente a forma geral da riqueza, ocultando seu significado, quando o objetivo da produção deixa de ser a produção de mercadorias para se tornar a valorização do próprio capital-dinheiro. No primeiro capítulo de O capital (1983a) Marx define o dinheiro como a representação geral da riqueza social, valor de troca que se torna independente das particularidades dos valores de uso, ou seja, tomando as palavras de Marx, a moeda é valor de troca objetivado e independente dos valores de uso e, enquanto tal, é diretamente social, em contraste com os valores de uso específicos. A moeda é valor de troca em sua generalidade, que se torna independente de qualquer forma específica de mercadoria, mas ao mesmo tempo é representada por alguma mercadoria que emerge do processo de troca. Cardim (CARVALHO, 1986) critica o procedimento de estender a teoria do valor diretamente para o valor da moeda, em termos de trabalho socialmente necessário para a produção das mercadorias. Ater-se à moeda-mercadoria significa subordinar a generalidade da moeda à particularidade da mercadoria que serve de meio de expressão, quando trocada pelo seu valor verdadeiro. Assim, a moeda poderia se tornar a forma geral da riqueza apenas através das especificidades de uma mercadoria específica.

A conclusão de Cardim parece lógica: sem abandonar a perspectiva da moedamercadoria é impossível desenvolver a teoria monetária de Marx de modo a explicar o desenvolvimento das relações monetárias e financeiras do capitalismo atual. Como bem acentuou Marx (1983a), a substância do dinheiro é a riqueza social e não o ouro. A teoria monetária de Marx é mais ampla e subsiste sem a moeda-mercadoria. Para tanto, Cardim sugere mudar o foco da análise da formação de valores para o da formação dos preços monetários. Em situação de equilíbrio, quando os preços representam os valores das mercadorias, a moeda deixa de ser relevante e não importa o que é moeda, qualquer coisa pode ser numerário ou mesmo meio de troca (CARVALHO, 1986, p. 18). O próprio Marx (1977, p. 153) havia afirmado que em situações de equilíbrio, a questão da moeda se torna inteiramente secundária.

Do mesmo modo, em situações de desequilíbrio, em que valores e preços divergem, não é necessário que a moeda seja uma mercadoria, por que não são os valores que se manifestam nos preços de mercado. E acrescenta que, na visão de Marx, a moeda é uma relação social alienada e mesmo "se representada por uma mercadoria, a moeda é sempre símbolo de uma relação social" (CARVALHO, 1986, p. 18). Enquanto ela for aceita socialmente, não importa o que representa esta relação social. $\mathrm{O}$ que importa é que o dinheiro continua sendo a conexão reificada entre produtores no tempo e no espaço. Marx (1977, p. 262) também já havia afirmado que "o papel-moeda e os numerosos representantes da moeda são as mais perfeitas formas de moeda e um estágio necessário no progresso do sistema monetário". Mais esclarecedor ainda se torna seu pensamento quando afirma que: 
Enquanto papel, a existência monetária das mercadorias tem uma existência puramente social. É a fé que traz a salvação. Fé no valor monetário como o espírito imanente das mercadorias, fé no modo de produção e sua disposição predestinada, fé nos agentes individuais de produção como meras personificações do capital, que se auto-valoriza. (MARX, 1981, p. 727)

Cardim conclui dizendo que seria difícil encontrar nas obras de Keynes e dos póskeynesianos "uma afirmação mais clara do caráter social da relação monetária e mais direta da indicação de que a visão de Marx sobre a moeda não precisará se restringir a moeda-mercadoria" (CARVALHO, 1986, p. 18).

\section{MARX E KEYNES: SEMELHANÇAS E DIFERENÇAS}

Cardim aponta "semelhança entre as propostas de Keynes e Marx em pontos fundamentais de suas visões da dinâmica do sistema capitalista" (CARVALHO, 1986, p. 19 ). Ao analisar a teoria monetária de Marx, a partir da visão pós-keynesiana, ele realça diferenças, mas, sobretudo, semelhanças entre o pensamento de Keynes e o de Marx que ultrapassam o campo da teoria monetária, embora estejam a ele fortemente relacionados. São essas semelhanças e diferenças, especificamente apontadas por Cardim, que desejamos analisar, e não o que outros autores propuseram, pois é através delas que ele procura estabelecer o diálogo entre Marx e Keynes.

Importa notar também que o autor não compara keynesianos e marxistas e sim o pensamento de Keynes e o de Marx, pois considera que, assim como ocorreu com o pensamento original de Keynes, que foi neoclassizado pelos autores keynesianos tradicionais, também ocorreu com os autores marxistas convencionais, cuja posição certamente não reproduz o pensamento original de Marx. Ou, por outras palavras, como afirma expressamente em seu texto sobre a teoria monetária de Marx (CARVALHO, 1986), a posição de muitos autores marxistas não traduz necessariamente a posição de Marx.

Há um outro paralelo interessante feito por Cardim, que ajuda a entender as dificuldades de um diálogo efetivo entre Keynes e Marx. Trata-se da influência dos modelos keynesianos tradicionais sobre o pensamento marxista convencional, de modo especial os teóricos marxistas do subconsumo. Ele critica tanto os modelos keynesianos tradicionais, para os quais a moeda não importa, como também critica os teóricos marxistas do subconsumo, a exemplo de Baran e Sweezy, os quais foram influenciados pela Teoria Geral de Keynes, a partir da ideia de que a concentração da renda provoca depressão através da propensão a consumir. 
Ao lado de semelhanças há também muitas diferenças entre Marx e Keynes em relação a suas concepções de capitalismo e às perspectivas sobre o futuro do sistema (PRADO, 2016, p. 124). Inicialmente, pode-se dizer que Marx elabora uma teoria crítica do capital, tendo em vista sua superação, enquanto Keynes procura reformar o capitalismo para que administre suas contradições e sobreviva indefinidamente. Os fundamentos dessa divergência sobre as perspectivas futuras do capitalismo podem ser buscados no próprio conceito de capital, que para Keynes se resume a um estoque de bens utilizados para produzir novos bens, enquanto que, para Marx, o capital é uma relação social reificada, um valor que faz da própria valorização sua finalidade última. Essa diferença teórica sobre a natureza do capital constitui a base das perspectivas diferentes de Marx e de Keynes, sobre o próprio sistema capitalista, pois, para Marx, o objetivo da produção no capitalismo não é produzir valores de uso, enquanto que, para Keynes, toda a produção se destina, em última análise, a satisfazer o consumidor, ou seja, seu objetivo é produzir valores de uso. Observe-se, no entanto, que essa afirmação pode estar em contradição com seu conceito de economia monetária, cuja finalidade é valorizar o capital-dinheiro e não produzir bens de consumo.

Em seu texto do Valor Econômico (CARVALHO, 2018), Cardim explicita o que seria sua principal divergência com relação ao pensamento de Marx. Como já foi mencionado acima, trata-se da visão de ciência, que ele atribui a Marx e que constituiria “o principal fator de afastamento" em relação a esse autor. É a partir da famosa afirmação de Marx de que, se essência e aparência fossem a mesma coisa, a pesquisa científica seria desnecessária, que Cardim resume, de forma simplificada, toda a complexa visão de Marx sobre a ciência. Para ele, ao contrário de Marx, "o trabalho científico não busca identificar ou explicar essências, por baixo ou por trás das aparências, mas identificar padrões nos dados que se observam, naquilo que aparece" (CARVALHO, 2018). Seria como "olhar para um tabuleiro e buscar a ordem nas peças". E conclui que "a ciência moderna não olha embaixo do tabuleiro, apenas o que está em cima, pois a informação é sempre visível” (CARVALHO, 2018).

Evidentemente, a visão de ciência exposta por Cardim é muito diferente da visão de ciência de Marx. Não é o caso, aqui, de discutir se a ciência moderna lida apenas com as aparências das coisas ou se busca explicar algo mais profundo na realidade. Ao mesmo tempo, cabe registrar que a partir da afirmação de Marx de que essência e aparência não coincidem, não se pode concluir que Marx tenha desprezado as pesquisas empíricas. Muito ao contrário, Marx não só valorizou como praticou ampla e exaustivamente a pesquisa empírica. Sua principal obra, O Capital, é o resultado teórico de mais de 30 anos de pesquisa empírica no Museu Britânico.

Consideradas essas diferenças teórico-conceituais e de perspectivas, dentre outras, é possível destacar pontos de convergência entre Keynes e Marx, como apontados no 
texto de Cardim (CARVALHO, 1986). Note-se que não se trata de assimilar um autor ao outro, mas apenas de examinar pontos de convergência entre Marx e Keynes especificamente apontados por Cardim, respeitadas as diferenças teóricas e metodológicas entre os dois autores.

A primeira e mais fundamental aproximação entre Marx e Keynes, realizada por Cardim, envolve a natureza da economia capitalista em sua finalidade ou a definição do capitalismo como uma economia essencialmente monetária. Como enfatiza ele (CARVALHO, 1986, p. 7), "para Marx, é apenas no modo de produção capitalista que a produção se orienta para a produção de valores de troca" e por isso o ciclo das mercadorias M-D-M se torna D-M-D', ou seja, uma economia em que o dinheiro (D) não desempenha apenas a função de moeda como meio de troca entre duas mercadorias (M). Ao contrário, trata-se de uma economia do tipo D-M-D', ou seja, uma economia cuja finalidade é valorizar o capital-dinheiro (D’). A fórmula original é de Marx e foi realçada pelo próprio Keynes nos rascunhos da sua Teoria Geral. Diz Keynes, referindo-se a Marx:

Ele mostrava que a natureza da produção no mundo presente não é, como os economistas parecem supor, um caso M-D-M, isto é, de troca de mercadoria (ou esforço) por dinheiro, a fim de obter outra mercadoria (ou esforço). Tal pode ser o ponto de vista do consumidor privado, mas não é a atitude que marca os negócios, que é um caso de D-M-D', isto é, de abrir mão de dinheiro para se obter mercadoria (ou esforço), a fim de se obter mais dinheiro. ... um empresário está interessado não na quantidade de bens, mas no volume de dinheiro que deverá caber-lhe. Este empresário aumentará sua produção caso, com isto, espere aumentar seu lucro monetário, embora seu lucro possa representar menos quantidade de produto que antes. (KEYNES, 1979, p. 81 e 82, grifos adicionados)

De acordo com esta expressão, D-M-D', a finalidade da produção deixa de ser a produção de mercadorias e passa a ser a de produzir mais-valor na forma de dinheiro, ou seja, D'. Isso implica que o mais-valor também precisa assumir a forma de dinheiro, o que ocorre através da realização da produção. A realização da produção é necessária, pois é através dela que os trabalhos privados individuais adquirem seu caráter social. É a partir da venda das mercadorias no mercado que se opera a coordenação indireta do sistema. Isso equivale ao reconhecimento social da atividade produtiva individual. Essa perspectiva teórica talvez seja o ponto mais importante do diálogo pensado por Cardim entre o pensamento de Marx e Keynes

Um segundo ponto possível de aproximação entre Marx e Keynes diz respeito à relação real-monetário. Para keynesianos e marxistas tradicionais, a moeda não tem 
papel relevante na produção, pois funciona apenas como meio de troca, dado que existe uma dicotomia entre mercados reais e mercados monetários. Da mesma forma como aconteceu com Keynes, cujos aspectos monetários foram relegados a um plano secundário por seus seguidores tradicionais, a moeda foi vista apenas como um problema, os aspectos monetários foram separados dos aspectos reais, consolidando a dicotomia real-monetário e a dinâmica econômica passou a ser explicada apenas em termos de fatores reais, assim também ocorreu com muitas versões marxistas do pensamento de Marx, que procuraram explicar a dinâmica capitalista a partir de variáveis reais, como realça Carvalho (1986, p. 5):

Esta linha de abordagem, que privilegia os mercados reais e relega aspectos monetários a posições subalternas, foi largamente adotada por autores marxistas que sofreram a influência dos modelos keynesianos. Na verdade, a ênfase tradicional na explicação marxista (mas não necessariamente na de Marx) da dinâmica capitalista, sempre foi dada a fatores reais, como a taxa de exploração, a composição orgânica do capital, etc., em abordagens onde variáveis monetárias ou financeiras servem a pouco mais do que dar algum colorido histórico à (sic) conclusões obtidas.

Foi o pensamento pós-keynesiano que resgatou a centralidade da moeda e dos processos monetários e financeiros no pensamento de Keynes. O mesmo aconteceu em relação ao resgate da importância do dinheiro e das relações monetárias e financeiras na dinâmica capitalista de acordo com o pensamento de Marx, como ele mesmo expressou ao colocar todo processo produtivo e de geração do mais-valor no âmbito do circuito do capital monetário, cuja valorização se define pela fórmula D-M-D’. Ao destacar a importância da teoria monetária em Keynes e em Marx, Cardim busca integrar o princípio da demanda efetiva de Keynes na dinâmica capitalista de Marx. Para ele, o princípio da demanda efetiva assumiu tal relevância na explicação de como funciona o capitalismo que não pode mais ser ignorado, nem para os mais ferrenhos opositores de Keynes.

É importante o destaque feito por Cardim, quando afirma que a partir dos anos 1960, as teorias (keynesianas ou marxistas) que estabeleceram uma clara separação entre aspectos reais e aspectos monetários já não conseguem explicar os processos capitalistas. Acentua também que essa redescoberta do papel dos fatores monetários na dinâmica capitalista se deve aos escritos de Keynes e especialmente aos desenvolvimentos teóricos do pensamento pós-keynesiano, para os quais o elemento mais revolucionário da obra de Keynes não é a propensão a consumir, mas a teoria da preferência pela liquidez, que opera como mecanismo de defesa contra a incerteza. Ao mesmo tempo, ele acentua ser inegável o papel fundamental do dinheiro na obra de Marx, 
embora isso nem sempre seja realçado por muitos autores marxistas, mas não por Marx e Keynes, como expressa enfaticamente: "Marx, como Keynes, recusou a dicotomia real x monetário e lançou as bases para uma teoria monetária bastante similar à de Keynes, hoje revivida pelos autores pós-keynesianos" (CARVALHO, 1986, p. 6).

Muito antes de Keynes, Marx já havia teorizado haver uma relação intrínseca entre o real e o monetário muito mais complexa e abrangente do que foi teorizado posteriormente também por Keynes. Para Marx, o monetário não é o oposto do real, mas uma forma de existência do próprio real, pois o real não são os valores de uso ou as mercadorias físicas, mas o valor, que assume uma forma monetária no dinheiro e no capital monetário. Nas palavras de Marx (1985, p. 47, 52 e 114): “enquanto valor, a mercadoria é dinheiro"; "o valor de troca da mercadoria constitui sua qualidade monetária imanente"; "o valor de troca forma a substância do dinheiro".

Efetivamente, para Marx, e também para Keynes, a economia capitalista é uma economia do tipo D-M-D', na qual o capital-dinheiro constitui, por isso, o ponto de partida e o ponto final de todo o processo de produção e de valorização.

A refutação da lei de Say, tanto por Marx como por Keynes, constitui o terceiro ponto de aproximação entre os dois autores. Como ressalta o próprio Carvalho (1986, p. 9), a dimensão temporal é essencial na teoria monetária de Marx, pois lhe "permitirá refutar a lei de Say do mesmo modo que permitiu a Keynes". Cardim assinala que, assim como Keynes e os pós-keynesianos, Marx refuta formalmente a lei de Say a partir da análise da simples troca de mercadorias. Como efetivamente afirmou Marx (1977, p. 200), a separação da troca em compra e venda torna possível comprar sem vender e vender sem comprar. Para Marx e para Keynes, a lei de Say, que afirma ser impossível uma situação de superprodução, está baseada na suposição de que produtos são trocados por produtos, ou de que a demanda é determinada apenas pela produção, o que equivale a afirmar que demanda e oferta são idênticas. Para Keynes, por ser considerada como um ativo, a moeda pode romper a unidade entre compra e venda, de modo semelhante ao que havia afirmado Marx. É esse papel ativo da moeda no modo de produção capitalista que cria a possibilidade geral das crises.

Efetivamente, Marx divide o ato da troca em dois momentos no tempo, o ato da venda e o ato da compra, a troca de mercadorias por moeda e a de moeda por mercadorias. Se numa troca direta entre mercadorias, a toda venda sucede uma compra e vice-versa, numa troca intermediada pela moeda, é possível vender sem comprar e comprar sem vender, como afirmou Marx: "A moeda não é apenas o meio pelo qual a troca é efetuada, mas é, ao mesmo tempo, o meio pelo qual a troca de produtos por produtos é dividida em dois atos, que são independentes entre si e separados no tempo e no espaço" (MARX, 1978, p. 504). Marx denomina essa divisão entre o ato de compra e o de venda da mercadoria como o "salto mortal da mercadoria", o qual ocorre no ato 
da venda da mercadoria por dinheiro (M' - D'), pois a produção capitalista não é planejada, de modo que a separação espaço-temporal que permeia a troca permite a não realização da produção e consequentemente a não realização do mais-valor D'.

Tanto para Marx quanto para Keynes, lembra Cardim, mercadoria não se troca por mercadoria. A necessidade de validação das decisões pelo mercado resulta da natureza alienada da produção capitalista, enquanto produção voltada para a criação de valores de troca. Ele associa essa questão ao conceito de reificação ou do fetichismo da mercadoria exposto por Marx em O Capital. O resultado da reificação seria a necessidade de transferir ao mercado a tarefa de organizar a alocação de recursos, inclusive o trabalho social, pois é no mercado que o produtor individual descobrirá se suas decisões foram acertadas ou não.

Um quarto ponto de comparação diz respeito ao papel autônomo ou subordinado dos indivíduos, sejam eles trabalhadores ou capitalistas, no processo de produção e valorização do capital. Aqui a aproximação entre a teoria de Marx e a de Keynes é mais complexa. Por um lado, Cardim destaca que o método de Marx é lógico-histórico, ou seja, que ele constrói sua teoria a partir de um comportamento histórico dos indivíduos e não de comportamentos humanos guiados por leis imutáveis. Nas suas palavras: "[a]o invés do agente racional walrasiano, suspenso no tempo e no espaço, os agentes econômicos em Marx têm motivações e comportamentos historicamente determinados, evoluindo e se alterando com as formas de organização social" (CARVALHO, 1986, p. 7).

A propósito, caberia esclarecer que, em Marx, não cabe a expressão "agentes econômicos" em sentido genérico, pois eles têm suas ações pautadas pela posição que ocupam na produção, ou seja, eles são ou capitalistas ou trabalhadores e suas ações são estruturalmente condicionadas. No caso presente, o agente econômico keynesiano corresponde ao capitalista, na perspectiva de Marx, para quem o homem não apenas age historicamente condicionado, mas também socialmente condicionado. É ele que faz a História, mas não a faz como deseja, o que equivale a dizer que ele não pode escolher arbitrariamente seu papel na História, pois este lhe é ditado pelas circunstâncias do processo social. Nesse sentido, o empresário capitalista, para Marx, tem suas decisões amarradas à lógica da valorização do capital, pois tende a se comportar como um "funcionário do capital". Assim, poder-se-ia dizer que tanto para Marx como para Keynes, o empresário capitalista tem suas ações condicionadas, quer pela lógica do capital, na expressão de Marx, quer pela incerteza radical, na expressão de Keynes. Respeitadas as devidas diferenças, é inegável que existe muita similaridade de pensamento entre os dois grandes pensadores a propósito deste tema.

Um quinto ponto relevante da aproximação entre Marx e Keynes se refere à relação dos produtores individuais com o mercado ou, por outras palavras, o problema da 
realização da produção individual, a qual envolve a questão da incerteza, tão crucial para Keynes e os autores pós-keynesianos, mas também presente em Marx. Para Keynes, trata-se de um problema ex-ante, ou seja, a decisão de produzir do empresário individual é precedida ou comandada pela expectativa de venda da produção futura no mercado. Em outras palavras, é a expectativa de demanda efetiva que move o empresário a tomar a decisão de produzir. Para Marx, trata-se de um problema ex-post, ou seja, um problema de realização da produção que se efetiva através da venda das mercadorias no mercado. Cardim associa esse processo na perspectiva de Marx ao que Keynes denomina de "expectativas de realização", que precedem as decisões de produção. O processo que, para Keynes, precede a tomada de decisão de produzir, como expectativa de venda, para Marx se daria ex-post, pela validação do mercado a uma produção individual já realizada. A citação de Rubin feita por Carvalho (1986, p. 8) é esclarecedora desta semelhança entre a teoria de Marx e a de Keynes:

Nós sabemos que os produtores de mercadorias, em suas atividade produtiva, levam em consideração o mercado e a situação de demanda, durante o processo de produção direta. Eles produzem e exclusivamente para transformar seu produto em dinheiro, e, assim, transformar seu trabalho concreto e privado em trabalho social e abstrato. Mas este modo de inserção de cada indivíduo no mecanismo social é apenas preliminar e conjetural. Ele tem ainda de submeter ao duro exame do processo de troca. Este exame pode mostrar resultados positivos ou negativos ao produtor de mercadorias. (RUBIN, 1979, p. 204-205)

O que Rubin está expressando, em termos de Marx, não é diferente da perspectiva pós-keynesiana de que a decisão de produzir se dá sob incerteza e a partir de conjecturas, ou seja, que as decisões de produzir de um empresário são tomadas sem que ele saiba ao certo sobre as decisões de outros empresários e, por isso, tem ele que adaptar suas decisões às decisões dos outros. A questão da incerteza, que cerca as decisões dos empresários produtores de mercadorias, como mencionado por Rubin, é sem dúvida uma questão relevante, tanto no pensamento de Marx, quanto no de Keynes, mas tem fundamentos e características diferentes nos dois autores. Em Marx, a incerteza surge não apenas associada à questão da realização do mais-valor produzido ou à concorrência entre os capitais, mas sobretudo associada à natureza do próprio capital, que atua como um processo no qual se inserem as decisões dos produtores individuais de mercadorias. O movimento do capital, como processo de produção e de valorização, se impõe sobre as decisões dos capitalistas individuais. Em Keynes, a questão da incerteza se diferencia da noção de risco e assume uma importância ainda maior, pois cerca as decisões de investir dos empresários, as quais se definem como decisões cruciais 
para o movimento da economia. Ela geralmente está associada à existência de ativos líquidos na economia e permite que parte da renda não se transforme em demanda efetiva e com isso impede que o próprio sistema, entregue a si mesmo, possa se aproximar de uma situação de pleno emprego. Para Keynes, as raízes da incerteza estão na influência da moeda no processo de produção. Para Marx, trata-se de incerteza relacionada ao movimento autônomo do capital e ao problema da realização. A demanda de moeda, enquanto forma geral do valor e da riqueza, é uma defesa face à incerteza que cerca o problema da realização.

Cardim também associa a questão da incerteza em Keynes ao conceito de alienação de Marx, realçando as similitudes dos dois conceitos. Embora considere que o conceito de alienação de Marx seja muito mais complexo que o de incerteza de Keynes, pondera que ambos servem para mostrar que o problema da realização, ou da conversão da mercadoria em dinheiro, é a forma essencial de validação das decisões dos produtores individuais. Nas suas palavras:

O conceito de alienação de Marx é muito mais complexo do que o de incerteza de Keynes. Ambos, no entanto, servem para mostrar que o problema da realização, da conversão de mercadorias em dinheiro, é o modo essencial de validar as decisões dos produtores. (...). A validação das decisões pelo mercado, em Marx, resulta da natureza alienada da produção capitalista, subordinada à produção de valores de troca. (CARVALHO, 1986, p. 10)

Ao propor a aproximação desses dois conceitos, ele adverte que não está propondo uma identidade entre os mesmos, mas apenas buscando explicitar as semelhanças de alguns de seus aspectos. É possível aproximar os dois conceitos, desde que seja superada a interpretação feita por autores marxistas que consideram os agentes econômicos como meros portadores de relações sociais e reduzem a praticamente nada o papel de decisões e ações individuais, pois tal perspectiva não é compatível em nenhum grau com uma visão pós-keynesiana. A incerteza não determina, mas condiciona e molda o comportamento dos agentes econômicos keynesianos, "que deve ser explicado socialmente" e não como se fosse a generalização de "atitudes de Robinsons Crusoés para situações de capitalismo avançado" (CARVALHO, 1986, p. 7). Do ponto de vista keynesiano, acentua ele, a incerteza está enraizada na influência da moeda nos processos capitalistas de produção, que demandam decisões e compromissos de financiamento em dinheiro, de tal modo que só podem ser saldados com com a venda da produção. Todas essas operações de produção, financiamento e venda envolvem incerteza. De modo semelhante, destaca a afirmação de Marx (1977, p. 198), segundo a qual: “[a] mercadoria não requer apenas demanda, mas demanda que pode ser paga em di- 
nheiro. Desse modo, se seu preço não pode ser realizado, se ela não pode ser transformada em dinheiro, a mercadoria torna-se desvalorizada”. Essa possibilidade se torna real quando a demanda efetiva é insuficiente. E, se os compromissos não puderem ser atendidos, a crise se espalha em cadeia e pode se generalizar.

No contexto da teoria da alienação de Marx, Carvalho (2018) conclui que "o agente econômico age em um ambiente que lhe é estranho, mesmo que este ambiente tenha sido produzido por ele". Ora, continua ele, "esse é também o quadro em que o conceito de incerteza proposto por Keynes se define, isto é, um ambiente construído, mas não reconhecido pelo indivíduo" (ibidem). Poderíamos dizer que, para Cardim, a raiz da incerteza keynesiana estaria numa situação não controlada pelos empresários, um contexto em que não há base segura para fazer previsões racionais sobre o futuro do investimento. Um contexto semelhante seria o da alienação de Marx, em que está mergulhado o trabalhador, que perde o controle sobre o produto de seu trabalho. Tanto os empresários de Keynes quanto os trabalhadores de Marx são dominados pelo contexto que ajudaram a criar. Essa aproximação do conceito de alienação de Marx com o conceito de incerteza de Keynes será objeto de análise mais adiante neste trabalho.

Um sexto ponto diz respeito à associação do caráter "diretamente social" da moeda em Marx e o conceito de liquidez de Keynes. Para Marx, a moeda tem um caráter diretamente social e para Keynes, a moeda se define pela sua liquidez, ou seja, para os dois autores, a moeda se define pela sua capacidade de conversão em qualquer mercadoria ou ativo de forma imediata e praticamente sem custo. A qualidade característica da moeda de ser por natureza diretamente social, na linguagem de Marx, não parece ser outra coisa se não sua liquidez, ou seja, que ela pode ser trocada por qualquer mercadoria, de forma imediata e sem custo, pois ela é por natureza a "mercadoria geral", o valor de troca "em pessoa", líquido e autônomo em relação aos valores de uso.

Para Marx, o dinheiro se torna objeto de demanda, porque não é apenas o meio de circulação das mercadorias existentes, mas também a conexão com as mercadorias a serem produzidas no futuro. A demanda especulativa de moeda para Keynes se torna uma arma de defesa contra as incertezas do futuro. De modo semelhante, para Marx, a moeda enquanto forma geral da riqueza, é uma forma perfeitamente líquida. Acumular riqueza na forma de dinheiro reduz os riscos associados à realização. É a incerteza sobre a convertibilidade que justifica acumular dinheiro, a forma de riqueza geral e perfeitamente líquida.

O sétimo ponto de comparação se refere à função de entesouramento da moeda em Marx, seu poder de transformar-se em tesouro, e o conceito de ativo de Keynes. Para Cardim, o conceito de moeda como um ativo, em Keynes, se refere à sua capacidade de conservar a riqueza no tempo, qualidade associada à sua função de reserva de valor. De modo semelhante, para Marx, a moeda é a mercadoria permanente, um "te- 
souro" indestrutível. Como tesouro, o dinheiro deixa de circular como moeda para assumir a forma de capital e pode ser acumulado, não como moeda, mas como capital. O desejo de entesourar é insaciável, diz Marx, traduzindo a expressão latina: "aura sacra fames". O possuidor de dinheiro deixa de desejá-lo em forma de mercadoria, pois as mercadorias são dinheiro perecível e o dinheiro é a mercadoria imperecível. A propósito, ele (CARVALHO, 1986, p. 11) cita a passagem dos Grundrisse, onde Marx reafirma essa perspectiva:

Se a moeda aparece como a mercadoria geral em todos os lugares, também o faz em qualquer tempo. Ela mantém-se como riqueza em qualquer tempo. Esta é sua durabilidade específica. É o tesouro que não enferruja nem é comido pelas traças. Todas as mercadorias são apenas o dinheiro transitório: o dinheiro é a mercadoria permanente. (MARX, 1977, p. 231)

Mesmo inseridos em contextos teóricos diversos, em algum sentido, esses conceitos de moeda como "tesouro que não enferruja, nem é comido pelas traças", como "mercadoria permanente" e de moeda como ativo possuem um núcleo central comum. Provavelmente Marx e Keynes estejam falando da mesma coisa com palavras diferentes.

Por fim, algumas considerações sobre a questão da instabilidade da economia capitalista. Embora Cardim não trate expressamente desse tema ao abordar a teoria monetária de Marx, o mesmo sem dúvida não só está presente na teoria monetária de Marx e de Keynes, mas também ocupa posição central no pensamento desses autores. Como ocorreu em relação aos demais temas aqui analisados, a instabilidade capitalista constitui elemento importante do diálogo entre Marx e Keynes buscado por Cardim. A questão da instabilidade está associada à possibilidade das crises na economia capitalista. Ao se referir às perspectivas de crise em Marx, associadas às próprias contradições internas do sistema capitalista, ele ressalva que, "[e]mbora o assunto pertença mais à teoria do ciclo que à teoria monetária, per se, é interessante notar que mesmo aqui a posição de Marx coincide com a de Keynes. Para este, é o colapso da eficiência marginal do capital que explica as crises" (CARVALHO, 1986, p. 10).

Vercelli (1985) faz um estudo comparativo sobre o que denomina de "instabilidade estrutural" do sistema econômico capitalista no pensamento de Marx, Keynes e Schumpeter. Para ele, a instabilidade estrutural do sistema está associada às propriedades da moeda e do crédito. As análises feitas por Cardim sobre a teoria monetária de Marx, numa perspectiva pós-keynesiana, fornecem elementos importantes para entender o papel da moeda e do crédito na criação da instabilidade e das crises. Vercelli (1985) entende a "instabilidade keynesiana" como uma "instabilidade cíclica”, que não afeta a estabilidade associada aos movimentos tendências do sistema. E a "instabili- 
dade marxista" é vista como um fenômeno efêmero no âmbito das tendências estáveis de longo prazo. Para Marx, a instabilidade capitalista está associada às mudanças estruturais, que não são provocadas por distúrbios externos e sim pelas contradições internas ao próprio sistema. Para Braga (1985), a instabilidade é uma propriedade da própria estrutura econômica, na perspectiva de Marx, e não apenas o resultado das decisões capitalistas, como se afigura na perspectiva de Keynes. O capital-dinheiro é o sujeito que ordena a estrutura, e, por isso, as decisões capitalistas dão-se sob a incerteza. A dinâmica e a instabilidade capitalista, conclui Braga, se configuram como um processo que associa o movimento do capital às decisões capitalistas, ou seja, a teoria da acumulação de Marx e teoria da demanda efetiva de Keynes interagem em planos mutuamente condicionantes na determinação da instabilidade estrutural da economia capitalista.

Nesta resenha de Cardim sobre a teoria monetária de Marx, numa perspectiva pós-keynesiana (CARVALHO, 1986), destacamos algumas diferenças do pensamento de Marx e Keynes, mas sobretudo os muitos pontos de convergência, que se constituem a base do suposto diálogo interrompido ou não ao longo da longa e profícua trajetória daquele autor.

Do nosso ponto de vista, no entanto, a principal limitação deste diálogo tentado por Cardim entre Marx e Keynes, a partir de uma perspectiva pós-keynesiana, reside na questão que já apontamos em texto anterior (CORAZZA, 1994), qual seja, notadamente a falta de um um conceito de dinheiro que esteja articulado com uma teoria do valor e com uma teoria do capital no pensamento de Keynes e de autores pós-keynesianos. Dillard (1954, p. 28) talvez tenha sido um dos primeiros autores keynesianos a mencionar a debilidade da teoria do capital na Teoria Geral de Keynes, quando afirmou que "uma debilidade fundamental da TG é a falta de uma teoria do capital”. Efetivamente, o que é o capital para Keynes? Conforme Prado (2016), um estoque de bens utilizados para produzir novos bens. Embora Keynes tenha feito alusão ao trabalho como base da produção e tenha definido a moeda como um ativo com propriedades especiais, no entanto, esses conceitos não estão articulados com uma teoria do valor. Em O Capital, Marx formula uma teoria da gênese do dinheiro a partir de uma teoria do valor, articulada com uma teoria do capital, entendido como um valor que se valoriza e que pode assumir diferentes formas, capital mercadoria, capital dinheiro, capital a juros e capital fictício. Torna-se difícil compreender o dinheiro, quando se parte do próprio dinheiro ou de uma de suas formas, seja ela o dinheiro-mercadoria, seja o dinheiro de crédito, seja mesmo o dinheiro-papel, sem lastro e inconversível. Para se compreender o dinheiro é preciso partir do valor. E, para se chegar ao capital é preciso partir do dinheiro que, no capitalismo, transforma-se em capital. 


\section{CONCLUSÃO}

Embora possa parecer paradoxal, para um autor que afirma ter se afastado de Marx ainda no período de sua formação, é inegável que seu texto sobre a teoria monetária de Marx a partir de uma perspectiva pós-keynesiana (CARVALHO, 1986) representa a possibilidade de um profícuo diálogo entre Marx e Keynes, confrontando conceitos teóricos e questões essenciais das teorias dos dois autores.

O referido texto possui o grande mérito de realçar elementos essenciais da teoria monetária de Marx. Primeiramente, o conceito de moeda tem uma dimensão histórica, no sentido de que sua natureza se define e pode mudar de acordo com seu papel e a natureza do sistema econômico em que a mesma está inserida. Assim, no sistema capitalista, a moeda, além de seu papel de meio de troca, pode assumir a forma e o papel de capital-dinheiro e deixar de ser meio para tornar-se sujeito do processo de produção e valorização. Nessa perspectiva histórica, ele acentua que a moeda em Marx se define como a materialização da relação social, uma relação social retificada, ou, ainda, como meio de validação social do trabalho individual. Embora tenha sugerido que a análise monetária de Marx possa ter se restringido ao sistema monetário do padrão-ouro, ele defende corretamente que a teoria monetária de Marx vai muito além da moeda-mercadoria. Associado ao fetiche da mercadoria, que esconde as relações sociais, está o conceito de alienação do trabalhador, que não controla o produto de seu trabalho. A alienação decorre da dominação do trabalho pelo capital, que atua como verdadeiro sujeito do processo econômico.

O seu interesse pela teoria monetária de Marx reside na tentativa de aproximar a teoria da demanda efetiva de Keynes com a dinâmica do processo de acumulação de capital de Marx. Para tanto, ele resgata a dimensão social da moeda definida por Marx no Livro I de O Capital, ao analisar a gênese do dinheiro, e sinaliza seu potencial de desenvolvimento a partir de outros conceitos elaborados por Marx nos Grundrisse e no Livro III de O Capital, como o de dinheiro de crédito, capital monetário, capital portador de juros e o de capital fictício. Tais conceitos são fundamentais para o desenvolvimento de uma teoria monetária e financeira na perspectiva de Marx. Embora tenha sinalizado para essa possibilidade, no entanto, o fato é que não encaminhou seus estudos nessa direção. Se assim o tivesse feito, certamente teria conseguido avanços enormes no desenvolvimento da teoria monetária e financeira de Marx. Ele chegou mesmo a propor expressamente, no seu texto, as condições para esse desenvolvimento, quais sejam: desenvolver as relações monetárias no contexto de sistemas bancários e financeiros e desenvolver uma teoria dos preços monetários de mercado em economias capitalistas. Seu grande mérito, no entanto, a par de ter apontado as similitudes de conceitos fundamentais das teorias de Marx e Keynes, foi ter realçado o conceito de moeda como a retificação das relações sociais e sinalizado seu potencial de desenvolvimento. 
Para concluir, voltamos à pergunta inicial: o suposto diálogo entre Marx e Keynes presente no pensamento de Cardim teria sido realmente interrompido? Embora ele afirme que sua ruptura com Marx tenha ocorrido ainda durante o mestrado, parece intrigante que logo após ter concluído o doutorado, com sua importante tese sobre Keynes e o pensamento pós-keynesiano, o primeiro texto que publicou tenha sido justamente sobre Marx. E não apenas sobre Marx, mas que tenha tratado precisamente da questão da moeda, quando esse não era ainda um tema central entre os próprios autores marxistas. Por que teria ele tentado estabelecer um diálogo entre Marx e Keynes justamente a partir da complexa e pouco discutida questão monetária em Marx? Por que não deu ele continuidade a esse diálogo ao longo de sua carreira acadêmica? Por que, nos seus dois últimos textos (CARVALHO 2011, 2018), teria ele se sentido motivado a fazer um balanço de sua relação teórica com Marx, após tantos anos de sua ruptura com o mesmo Marx? É difícil e até temerário pretender dar uma resposta clara e convincente a essas perguntas intrigantes. O que parece mais razoável concluir é que, se o diálogo com Marx, que estabeleceu a partir de Keynes, chegou a ser em algum momento realmente interrompido, suas inquietações com as ideias de Marx nunca o abandonaram. No final da vida, Marx ainda o inquietava.

\section{REFERÊNCIAS}

AKB - ASSOCIAÇÃO KEYNESIANA BRASILEIRA. Conversas com economistas pós-keynesianos - I Fernando Cardim de Carvalho. Blog da AKB, 19 jul. 2011. Disponível em: < https://jlcoreiro.wordpress.com/2011/07/19/conversas-com-economistas-pos-keynesianos-i-fernando-cardim-de-carvalho/>.

BRAGA, J. C. de S. Temporalidade da riqueza. Tese (Doutorado em Economia) - Instituto de Economia, Universidade Estadual de Campinas, Campinas, SP, 1985. Mimeo.

BRUNHOFF, S. de. La monnaie chez Marx. Paris: Editions Sociales, 1967.

CARVALHO, F. C. J. Meu encontro (e desencontro) com Marx. Valor Econômico, 27 abr. 2018. Disponível em: < https://valor.globo.com/eu-e/noticia/2018/04/27/meu-encontro-e-desencontro-com-marx.ghtml>.

CARVALHO, F. C. J. A teoria monetária de Marx: uma interpretação pós-keynesiana. Revista Brasileira de Economia Política, v. 6, n. 4, out./dez. 1986.

CORAZZA, G. Marx e Keynes sobre dinheiro e economia monetária. Revista da Sociedade Brasileira de Economia Política, v. 2, n. 3, p. 45-58, 1998.

CORAZZA, G. O real e o monetário em Marx. Economia Ensaios, v. 15, n. 2, p. 43-57, jul. 2001.

CORAZZA, G. O dinheiro como forma de valor. Revista da Sociedade Brasileira de Economia Política, n. 11, dez. 2002. 
CORAZZA, G. Dinheiro, instabilidade e gestão monetária: de Minsky a Marx. Ensaios FEE, v. 15, n. 1, 1994.

DILLARD, D. Teoria de uma economia monetária. In: KURIHARA, K. (Org.). Economia PósKeynesiana. Cidade do Mexico: Aguilar, 1954.

DILLARD, D. Keynes and Marx: a centennial appraisal. Journal of Post-Keynesian Economics, v. 6, n. 3, 1984.

KEYNES, J. M. Collected writings of John Maynard Keynes. London: Macmillan, 1979, v. 29.

MARX, K. Capital. Harmondsworth: Penguin/New Left Review, 1976, v. 1.

MARX, K. Capital. Harmondsworth: Penguin/New Left Review, 1981, v. 3.

MARX, K. Grundrisse. Harmondsworth: Penguin/New Left Review, 1977.

MARX, K. O capital - Crítica da economia política. Livro primeiro. São Paulo: Abril Cultural, 1983a, v. 1.

MARX, K. O capital - Crítica da economia política. Livro primeiro. São Paulo: Abril Cultural, 1983b, v. 3.

MÉSZÁROS, I. Marx’s theory of alienation. New York: The Merlin Press, 1975.

MOLLO, M. L. R. Instabilidade do capitalismo, incerteza e papel das autoridades monetárias: uma leitura de Minsky. Revista de Economia Política, v. 8, n. l, jan./mar. 1988.

MOLLO, M. L. R. Marxista e pós-keynesiana. Revista Brasileira de Economia Política, v. 37, n. 1 (146), p. 259-261, jan./mar. 2017.

PRADO, E. Como Marx e Keynes demarcam o campo da macroeconomia. Revista da Sociedade Brasileira de Economia Política, n. 45, out./dez. 2016.

RUBIN, I. Ensaio sobre la teoria marxista del valor. Cidade do México: Siglo XXI, 1979.

TAVEIRA, A. P.; CLEMENTE, L.; CLEMENTE, A. Demanda efetiva em Marx e Keynes: uma crítica às tentativas de assimilação. In: ENCONTRO NACIONAL DE ECONOMIA DA REGIÃO SUL - ANPEC SUL, 16, Curitiba, Paraná, 13-14 jun. 2013.

VERCELLI, A. Keynes, Schumpeter, Marx and the structural instability of capitalism. Cahiers d'Économie Politique, n. 10-11, p. 279-304, 1985. 